\title{
Delayed formation of zero-valent selenium nanoparticles by Bacillus mycoides SelTE01 as a consequence of selenite reduction under aerobic conditions
}

Silvia Lampis ${ }^{1 *}$, Emanuele Zonaro ${ }^{1}$, Cristina Bertolini ${ }^{1}$, Paolo Bernardi ${ }^{2}$, Clive S Butler ${ }^{3}$ and Giovanni Vallini ${ }^{1}$

\begin{abstract}
Background: Selenite $\left(\mathrm{SeO}_{3}{ }^{2-}\right.$ ) oxyanion shows severe toxicity to biota. Different bacterial strains exist that are capable of reducing $\mathrm{SeO}_{3}{ }^{2-}$ to non-toxic elemental selenium $\left(\mathrm{Se}^{0}\right)$, with the formation of Se nanoparticles (SeNPs). These SeNPs might be exploited for technological applications due to their physico-chemical and biological characteristics. The present paper discusses the reduction of selenite to SeNPs by a strain of Bacillus sp., SelTE01, isolated from the rhizosphere of the Se-hyperaccumulator legume Astragalus bisulcatus.
\end{abstract}

Results: Use of $16 \mathrm{~S}$ rRNA and GyrB gene sequence analysis positioned SelTE01 phylogenetically close to B. mycoides. On agarized medium, this strain showed rhizoid growth whilst, in liquid cultures, it was capable of reducing 0.5 and $2.0 \mathrm{mM}$ $\mathrm{SeO}_{3}{ }^{2-}$ within 12 and 24 hours, respectively. The resultant $\mathrm{Se}^{0}$ aggregated to form nanoparticles and the amount of $\mathrm{Se}^{0}$ measured was equivalent to the amount of selenium originally added as selenite to the growth medium. A delay of more than 24 hours was observed between the depletion of $\mathrm{SeO}_{3}{ }^{2}$ and the detection of SeNPs. Nearly spherical-shaped SeNPs were mostly found in the extracellular environment whilst rarely in the cytoplasmic compartment. Size of SeNPs ranged from 50 to $400 \mathrm{~nm}$ in diameter, with dimensions greatly influenced by the incubation times. Different SelTE01 protein fractions were assayed for $\mathrm{SeO}_{3}{ }^{2-}$ reductase capability, revealing that enzymatic activity was mainly associated with the membrane fraction. Reduction of $\mathrm{SeO}_{3}{ }^{2-}$ was also detected in the supernatant of bacterial cultures upon NADH addition.

Conclusions: The selenite reducing bacterial strain SelTE01 was attributed to the species Bacillus mycoides on the basis of phenotypic and molecular traits. Under aerobic conditions, the formation of SeNPs were observed both extracellularly or intracellullarly. Possible mechanisms of $\mathrm{Se}^{0}$ precipitation and $\mathrm{SeNPs}$ assembly are suggested. $\mathrm{SeO}_{3}{ }^{2-}$ is proposed to be enzimatically reduced to $\mathrm{Se}^{0}$ through redox reactions by proteins released from bacterial cells. Sulfhydryl groups on peptides excreted outside the cells may also react directly with selenite. Furthermore, membrane reductases and the intracellular synthesis of low molecular weight thiols such as bacillithiols may also play a role in $\mathrm{SeO}_{3}{ }^{2-}$ reduction. Formation of SeNPs seems to be the result of an Ostwald ripening mechanism.

Keywords: Bacillithiol, Bacillus mycoides SelTE01, Extracellular precipitation, Intracellular deposition, Ostwald ripening mechanism, Redox regulation, Selenite reduction, TEM analysis, Xenobiotic detoxification, Zero-valent selenium nanoparticles

\footnotetext{
*Correspondence: silvia.lampis@univr.it

'Department of Biotechnology, University of Verona, Strada le Grazie 15,

Verona 37134, Italy

Full list of author information is available at the end of the article
}

\section{Biomed Central}

(c) 2014 Lampis et al.; licensee BioMed Central Ltd. This is an Open Access article distributed under the terms of the Creative Commons Attribution License (http://creativecommons.org/licenses/by/2.0), which permits unrestricted use, distribution, and reproduction in any medium, provided the original work is properly credited. The Creative Commons Public Domain Dedication waiver (http://creativecommons.org/publicdomain/zero/1.0/) applies to the data made available in this article, unless otherwise stated. 


\section{Background}

Although selenium can be considered an essential micronutrient for living systems at low concentrations, it becomes toxic at greater doses and the range between dietary deficiency $\left(<40 \mu \mathrm{g} \mathrm{day}^{-1}\right)$ and excess $\left(>400 \mu \mathrm{g} \mathrm{day}^{-1}\right)$ is fairly narrow [1]. Selenium generally occurs in relatively low amounts in geological raw materials (e.g. native rocks and ores), soils and sediments, but its contents in coals and crude oils can reach hundreds of $\mathrm{mg} \mathrm{kg}^{-1}$ in certain cases [2]. Concentrations in soils and sediments vary geographically, depending on the parent rock, ranging from $0.01 \mathrm{mg} \mathrm{kg}^{-1}$ in deficient areas to $1200 \mathrm{mg} \mathrm{kg}^{-1}$ in organic rich soils in toxic areas [3]. Therefore, selenium contamination represents an important public health concern and requires remediation initiatives especially in those geographic locations where agricultural irrigation drainage waters transport significant amounts of Se by leaching seleniferous soils. Furthermore, industrial activities such as oil refining, phosphate and metal ore mining and coal fire-based power production can all contribute to the dispersion of selenium in the environment. Se is also used extensively in both the electronics and glass industry and is added to animal feeds and food supplements. Other applications are in photocopying, in metal alloys for batteries, in vulcanized rubber manufacturing, in production of pigments, ceramics, plastics and lubricants, and in formulation of specific commodities such as anti-dandruff shampoos [4]; all of which ensure possible routes for the mobilization of selenium in the biosphere. Selenium occurs in four valence states: selenate $\left(\mathrm{Se}^{6+}\right)$, selenite $\left(\mathrm{Se}^{4+}\right)$, selenide $\left(\mathrm{Se}^{2-}\right)$, and elemental selenium $\left(\mathrm{Se}^{0}\right)$, and can form compounds with oxygen, sulfur, metals, and/or halogens [5]. The environmental fate and the toxicity of selenium strongly depend on its chemical speciation, with water soluble, oxidized forms (oxyanions) selenite $\left(\mathrm{SeO}_{3}{ }^{2-}\right)$ and selenate $\left(\mathrm{SeO}_{4}{ }^{2-}\right)$ showing severe toxicity to biota $[5,6]$. Microorganisms play a major role in the biogeochemical cycle of selenium in the environment [7]. Certain strains, that are resistant to selenium oxyanions and reduce selenite and/or selenate to the less available elemental selenium or to methylated Se forms [8], may be potentially used for the bioremediation of contaminated soils, sediments, industrial effluents, and agricultural drainage waters. It is worth noting that a large number of bacterial species, residing in diverse terrestrial and aquatic environments, possess the ability to reduce selenite and selenate into elemental selenium. This can occur through both enzymatic or non enzymatic mechanisms, leading to the formation of Se nanostructured particles (SeNPs) which are deposited inside the cell (cytoplasmic), within the periplasm or extracellularly [9-14]. Evidence exists that the microbial reduction of selenite occurs under both anaerobic and aerobic conditions. However, to date, anaerobic respiration is considered the most likely mechanism for selenite transformation to $\mathrm{Se}^{0}$ by means of dissimilative metabolism [15-18]. Anaerobic respiration of selenite has also been shown to involve selenite and/or selenate reductases, nitrite reductases and sulfite reductases [11,18-20]. Furthermore, the involvement of thiol-containing proteins such as glutathione has even been identified in some Gram negative bacteria capable of anaerobic reduction of $\mathrm{Se}_{3}{ }^{2-}$ to amorphous $\mathrm{Se}^{0}$ nanoparticles [21].

These particular SeNPs display special physical characteristics such as photoelectric, semiconducting and $\mathrm{X}$-ray-sensing properties [22] which make them attractive for possible nano-technological applications. They also possess adsorptive ability, antioxidant functions and due to their high surface area-to-volume ratio, a marked biological reactivity [23]; including anti-hydroxyl radical efficacy, a protective effect against DNA oxidation [24] and anti-microbial activity. Indeed, SeNPs have been found to strongly inhibit growth of Staphylococcus aureus, a key bacterial pathogen commonly occurring in human infections [25]. However, concern is now growing for the environmental impact of nanoparticle synthesis based on physico-chemical methods that require for high pressures and temperatures, are energy consuming, use toxic chemicals, and generate hazardous by-products. Consequently, applications using biological systems such as microbial cultures for the production of metal nanoparticles, including SeNPs, are becoming increasingly a realistic perspective. In the present paper the reduction of selenite by a strain of Bacillus sp. (previously classified as Bacillus mycoides SeITE01 [26]) has been investigated. This strain has been shown to be highly resistant to selenite (up to $25 \mathrm{mM}$ ) and able to transform this oxyanion into elemental SeNPs. In particular, a detailed comparison is given between the dynamics of disappearance of selenite from the growth medium and the appearance of SeNPs. Evidence is also provided for the SeNPs formation to be mainly in the extracellular environment. Based on the findings of microscopic analyses, coupled with biochemical and metabolic assays, hypotheses are advanced about possible mechanisms of reduction of selenite by $B$. mycoides SeITE01, compatible with the appearance of $\mathrm{Se}^{0}$ nanoparticles both inside or outside the bacterial cell.

\section{Results and discussion}

\section{Taxonomic identification of the strain SeITE01}

The bacterial strain SeITE01 was isolated from the rhizosphere of the Se-hyperaccumulator plant Astragalus bisulcatus grown on a Se-polluted soil through enrichment cultures spiked with $2.0 \mathrm{mM}$ sodium selenite, as described previously [26]. It was originally hypothesized that strain SeITE01 belonged to the Bacillus mycoides species on the basis of partial 16S rRNA gene sequence. In the present work, a combined approach using both gene sequencing 
analysis and evaluation of morphological traits has provided strain SeITE01 with a definitive taxonomic position.

Sequencing of the whole $16 \mathrm{~S}$ rRNA gene confirmed that strain SeITE01 can be associated to the Bacillus cereus group which includes $B$. cereus, $B$. thuringensis, $B$. anthracis, $B$. mycoides, $B$. pseudomycoides, B. cytotoxicus and $B$. wheihenstephanensis [27]. Similarity values for $16 \mathrm{~S}$ rRNA gene obtained through EZ-Taxon server [28] provided strain SeITE01 identity percentages of 99.53 and $99.40 \%$ with $B$. thuringensis and B. mycoides respectively; 99.31\% with $B$. wheihenstephanensis; $99.27 \%$ with B. cereus and B. anthracis, and $98.58 \%$ with B. pseudomycoides. Neighbor-joining (N-J) phylogenetic tree showed that SeITE01 is very close to $B$. mycoides and $B$. wheihenstephanensis since they formed a separate cluster (Figure 1).
These high similarity values are not surprising due to the very close relatedness among species within the $B$. cereus group which only differ from each other by zero through nine nucleotides in $16 \mathrm{~S}$ rRNA gene sequences [29]. Thus, the mere analysis of ribosomal genes is not enough to definitively establish the attribution of the strain SeITE01 to any given species. For this reason, partial sequencing of GyrB gene [30], coding for the subunit B of the gyrase enzyme, was performed allowing the confirmation of a close connection of SeITE01 with B. mycoides and B. wheihenstephanensis on the basis of the $\mathrm{N}-\mathrm{J}$ philogenetic tree (Figure 2).

Phenotypic analysis of the bacterial growth showed that SeITE01 spreads on Nutrient agarized plates with thin, branching projections (rhizoid growth) (Figure 3). This

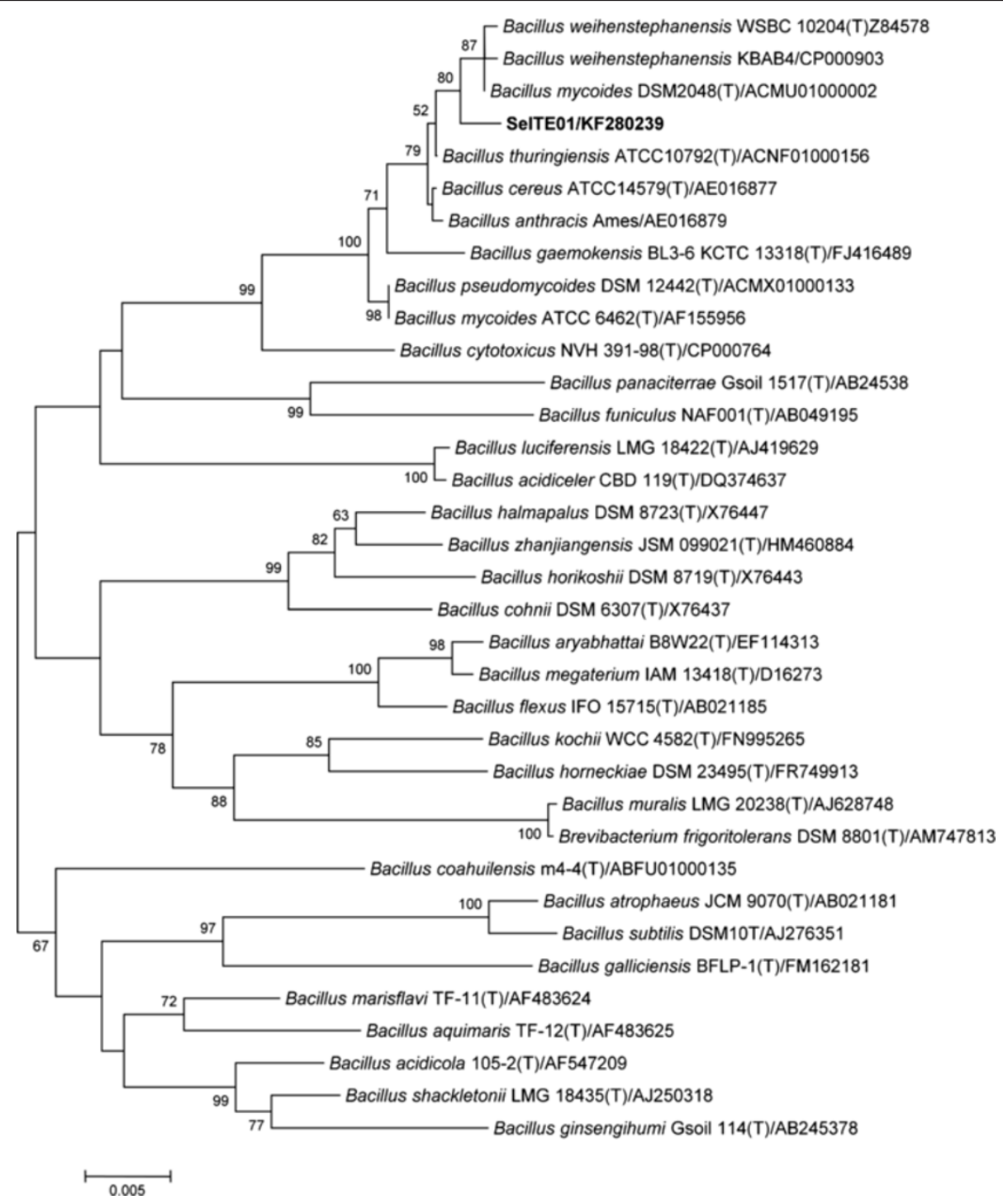

Figure 1 Neighbour-joining tree inferred through MEGA 5.0 software [61] based on the sequences of 16S rRNA gene, showing the phylogenetic relationship of strain SelTE01 and related species. Bootstrap values are shown for nodes that had $>50 \%$ support in a bootstrap analysis of 1000 replicates. The scale bars indicate the number of substitutions per nucleotide position. 


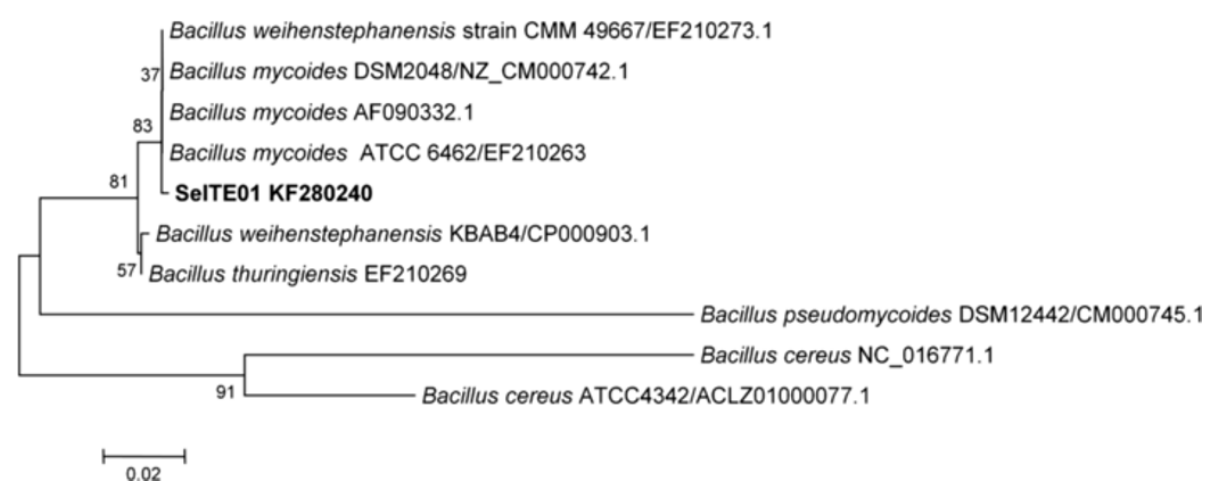

Figure 2 Neighbor-joining tree inferred through MEGA 5.0 software [61] based on the sequences of GyrB gene, showing the phylogenetic relationship of strain SelTE01 and related species. Bootstrap values are shown for nodes that had $>50 \%$ support in a bootstrap analysis of 1000 replicates. The scale bars indicate the number of substitutions per nucleotide position.

elaborated chiral colony pattern was first described as a typical trait of Bacillus mycoides species by Flügge in 1886. The author called the species "mycoides" just due to fungal-like growth of these rod shaped bacteria on agar plates with filaments of chained cells projecting radially and turning left or right [31]. Interestingly, this phenotypic trait is however absent in B. wheihenstephanensis [32]. Thus, on the basis of such molecular and phenotypic features, the strain SeITE01 can be taxonomically positioned at the branch tip of the B. mycoides species.

B. mycoides is a common soil bacterium, occurring in the rhizosphere of different plant species. A number of studies report on the contribution of this bacterial species to the Induced Systemic Resistance (ISR) in plants even by PGP (plant growth promoting) traits [33]. In general, Bacillus has been recognized for its biotechnological applications at an industrial scale. Recent investigations have shown the potential of Bacillus species to generate biofuels (e.g. hydrogen), biopolymers (e.g. polyhydroxyalkanoates), and bioactive molecules (e.g. acyl-homoserine lactonases) [34]. Moreover, several strains of Bacillus sp. have been considered for bioremediation due to their degradative efficiency toward toxic organic compounds and their capacity of reducing oxyanions such as selenate and selenite to elemental selenium with formation of $\mathrm{Se}^{0}$ nanoparticles (SeNPs) [11,12,16,35-37].

\section{Testing for selenite reduction and elemental selenium formation by the strain SelTE01}

The capability of SeITE01 to transform selenite to elemental selenium was tested in liquid rich medium (Nutrient Broth) at 0.5 and $2.0 \mathrm{mM}$ concentration of $\mathrm{Na}_{2} \mathrm{SeO}_{3}$ (Figure 4). Selenite concentration in the growth medium, elemental selenium content, and bacterial growth were all measured.

Due to the reduction of selenite, strain SeITE01 displayed a progressive depletion of the $\mathrm{SeO}_{3}{ }^{2-}$ initially added to the culture medium (Figure 4). Reduction of selenite was observed within 12 and 24 hours, when 0.5 and $2.0 \mathrm{mM} \mathrm{SeO}_{3}{ }^{2-}$ were supplied, respectively. At both selenite concentrations tested, the reduction process started concomitantly with the onset of the microbial growth. No
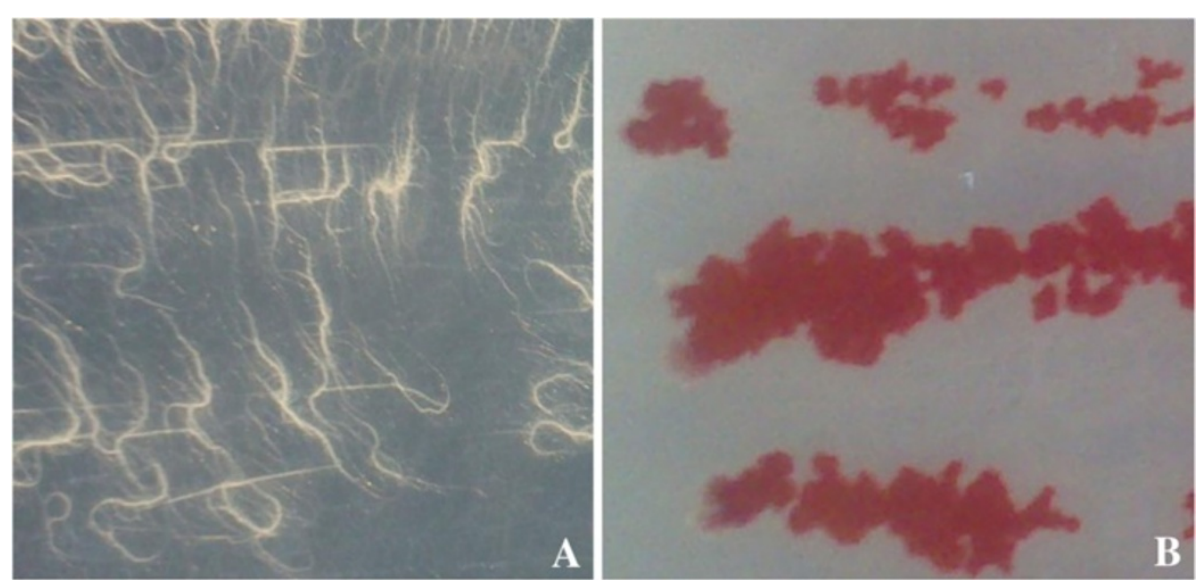

Figure 3 Growth of Bacillus SelTE01 on agarized medium in absence (A) and presence (B) of $2.0 \mathrm{mM}$ selenite. 

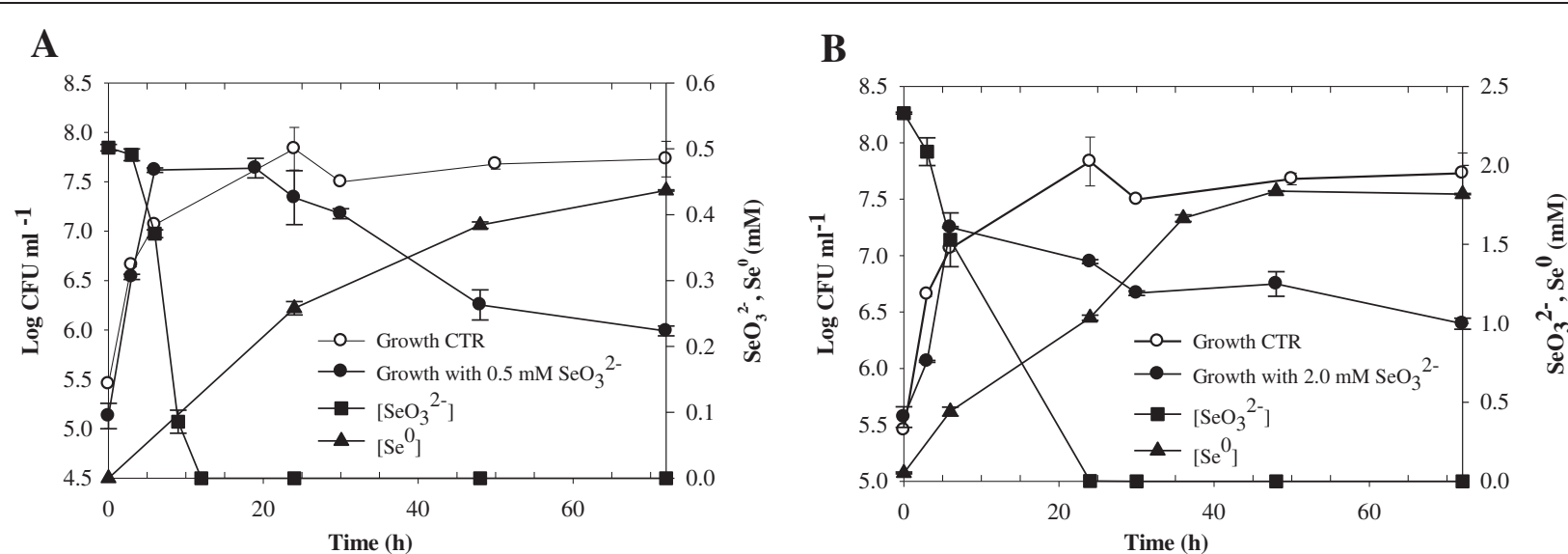

Figure 4 Time courses of bacterial growth, $\mathrm{SeO}_{3}{ }^{2-}$ depletion, and $\mathrm{Se}^{0}$ formation by $\mathrm{B}$. mycoides SelTE01, in presence of (A) 0.5, and (B) $2.0 \mathrm{mM} \mathrm{SeO}_{3}{ }^{2-}$. Each curve shows means based on the results of three experiments. Minor ticks (5-hours range) are inserted in the Time axis.

lag phase was observed thus suggesting a constitutive reduction pathway. In the presence of $0.5 \mathrm{mM} \mathrm{SeO}_{3}{ }^{2-}$, the total amount of selenite initially added to the cultures was exhausted during the exponential phase of growth. By contrast, when $2.0 \mathrm{mM} \mathrm{SeO}_{3}{ }^{2-}$ was supplied, only $25 \%$ of the initial selenite content was reduced during the exponential phase, the remaining selenite being depleted during the stationary phase.

$\mathrm{SeO}_{3}{ }^{2-}$ negatively affected the growth dynamics of SeITE01 and final cell yield (Figure 4). At the beginning of the stationary phase no significant differences were observed on cell concentrations between selenitesupplemented cultures compared with controls. Nevertheless, the stationary phase was reached by SeITE01 more rapidly with $\mathrm{SeO}_{3}{ }^{2-}$ in the medium than in cultures without selenite. In particular, for cultures with no selenite added, the stationary phase was reached after about 24 hours, whereas in cultures containing $\mathrm{SeO}_{3}{ }^{2-}$ the stationary phase was attained after only 6-10 hours of growth. When selenium was added as $0.5 \mathrm{mM} \mathrm{SeO}_{3}{ }^{2-}$, stationary phase was prolonged up to the 20th hour with values comparable to those seen with control cultures. After 20 hours of incubation, a decrease in cell growth was observed corresponding to a reduction of about 0.1 Log units in the final cell yield with respect to control experiments. In cultures spiked with $2.0 \mathrm{mM} \mathrm{SeO}_{3}{ }^{2-}$, a decrease in cell growth was recorded just after 6 hours of incubation. These culture conditions also resulted in a lower final cell yield ( 1 unit Log) when compared to controls. Therefore, it seems clear that selenite exerts a toxic effect on the growth of SeITE01 with toxicity dependent on $\mathrm{SeO}_{3}{ }^{2-}$ concentration. These data suggested that rate and efficiency of selenite reduction are most likely related to both the initial selenite concentration and the total number of bacterial cells, rather than to the bacterial growth phase.
Reduction and consequent depletion of $\mathrm{SeO}_{3}{ }^{2-}$ were accompanied by the appearance of a bright red color in the growth medium. This characteristic red color was due to excitation of the surface plasmon vibrations of the monoclinic selenium (m-Se) particles [38]. Despite the reduction process running parallel to the microbial growth, red color in cell suspensions appeared later. In particular, bacterial cultures turned red after 6 and 9 hours from the start of the growth assays when supplied with 0.5 , and $2.0 \mathrm{mM} \mathrm{SeO}_{3}{ }^{2-}$, respectively.

These results were in agreement with elemental selenium levels measured in bacterial cultures. In the presence of $0.5 \mathrm{mM} \mathrm{SeO}_{3}{ }^{2-}$, although the initial amount of selenite was completely depleted after 12 hours of incubation, only $\sim 25 \%$ of it was transformed into detectable $\mathrm{Se}^{0}$. Moreover, after 24 and 72 hours of incubation, only 50\% and 90\% of initial selenite was respectively converted into elemental selenium. Similar results were observed when $2.0 \mathrm{mM}$ selenite was added to the cultures. While the whole initial $\mathrm{SeO}_{3}{ }^{2-}$ content was completely reduced within 24 hours of growth, only about $50 \%$ of it was transformed into $\mathrm{Se}^{0}$ and about $88 \%$ of selenite resulted in the formation of $\mathrm{Se}^{0}$ after 72 hours. Thus, at both selenite concentrations tested, $\mathrm{Se}^{0}$ bioprecipitation was delayed in respect to selenite depletion in the culture medium.

This indicated that $\mathrm{SeO}_{3}{ }^{2-}$, before ultimate reduction to $\mathrm{Se}^{0}$, is likely transformed to an intermediate Se reduced form. This phenomenon has been previously observed also by Van Fleet-Stalder and co-workers [39] while studying a Rhodobacter sphaeroides strain capable of reducing selenite to red elemental selenium. These authors demonstrated that their bacterial strain metabolized selenite into approximately $60 \%$ RSeR and $40 \%$ $\mathrm{Se}^{0}$ when it was supplied with low selenite concentration $(10 \mu \mathrm{M})$ but produced almost $100 \% \mathrm{Se}^{0}$ after exposure to $1.0 \mathrm{mM}$ selenite. 
Again, Sarret and colleagues demonstrated that selenite addition into cultures of Ralstonia metallidurans $\mathrm{CH} 34$ was followed by a lag of slow uptake, during which the bacteria contained $\mathrm{Se}^{0}$ and alkyl selenide in equivalent proportions [40]. Subsequently, selenite uptake strongly increased and $\mathrm{Se}^{0}$ resulted as the predominant transformation product, suggesting an activation of selenite transport and reduction systems after several hours of contact. The authors indicated that two reactions took place in $R$. metallidurans $\mathrm{CH} 34$ : an assimilatory pathway leading to alkyl selenide and a detoxification pathway leading to $\mathrm{Se}^{0}$. The identification of a SAM dependent methyltransferase $(\mathrm{SefB})$ in an operon adjacent to the SeNP assembly protein SefA in $T$. selenatis has also suggested a link between both reductive and alkyl-selenide dependent selenite detoxification [14]. Moreover, Kessi and Hanselmann, while investigating the possible involvement of the Painter type reaction in selenite reduction to elemental selenium in Rhodospirillum rubrum and Escherichia coli, hypothesized at first a quick formation of a selenium-digluthathione intermediate followed by elemental selenium production [21].

\section{Localization of $\mathrm{Se}^{0}$ nanoparticles in SelTE01 cultures}

TEM analysis (Figure 5) revealed the presence of extracellular electron-dense particles after 12 (Figure 5A) and 24. (Figure 5B) hours of SeITE01 incubation in cultures supplemented with $2.0 \mathrm{mM}$ selenite. Only in very few cases, particles of the same aspect could be observed in the cytoplasm. Electron-dense granules were not detected in cell cultures which had not received $\mathrm{SeO}_{3}{ }^{2-}$ (data not shown). These nanoparticles seemed to be embedded in an extracellular matrix probably formed by components actively secreted or leaked out of damaged cells. However, spoiled cells or cell-like structures lacking internal organization were rarely identified in specimens examined by TEM.

EDX spectra of these nanospheres clearly indicated the presence of selenium, as the specific absorption peaks at 1.37, 11.22, and $12.49 \mathrm{keV}$ were recorded (Figure 5C, D). $\mathrm{Cu}$ and $\mathrm{Ni}$ peaks could be associated with the TEM grid, whereas $\mathrm{O}$ and $\mathrm{C}$ peaks are most likely from cell components. The lack of peaks corresponding to other metals signified that selenium occurred in its elemental state $\left(\mathrm{Se}^{0}\right)$ rather than as a metal selenide. Exposure of SeITE01 cultures to $2 \mathrm{mM} \mathrm{SeO}_{3}{ }^{2-}$ also induced formation of white granules of polyhydroxybutyrate possibly connected to stress conditions (Figure $5 \mathrm{~B}$ and $\mathrm{C}$ ) and caused a slight increase (1.5 time on average) of the bacterial cell length (data not shown).

SEM-EDX analysis carried out at different incubation times on cultures grown on $2.0 \mathrm{mM} \mathrm{SeO}_{3}{ }^{2-}$, confirmed the presence of extracellular $\mathrm{Se}^{0}$ nanospheres during early phases of the bacterial growth (after 6 hours of incubation) (Figure 6). Given that it is unlikely that particles of the size observed could be transported first through the plasma membrane with a vesicle-mediated excretion mechanism and then through the thick peptidoglican wall. It is therefore reasonable to infer that the reduction of selenite primarily occurs in the extracellular environment. However an ancillary mechanism of selenite reduction seems to exist, involving elemental selenium formation within the cell, either in the periplasm or in the cytoplasm, as confirmed by TEM analysis.

SeNPs appeared spherical or oblong in shape and decidedly dishomogeneous in terms of size. Both number and dimensions of these particles rose by increasing incubation time. Figure 6B shows that SeNPs possess an average diameter of 50-100 nm after 6 hours of incubation, coinciding with the exponential phase of bacterial growth, while in the late stationary phase (after 48 hours of growth) their dimensions range from 50 to $400 \mathrm{~nm}$ (Figures 5 and 6). This suggests that small nanoparticles, produced early in the growth phase, can behave as seeds of nucleation for further growth through a maturing process resembling the Ostwald ripening phenomenon [38].

Results in agreement with those here presented have been described for other bacterial strains able to induce the formation of $\mathrm{Se}^{0}$ nanoparticles by selenite reduction. Bacillus subtilis, Pantoea agglomerans UC-32 and Shewanella sp. HN-41 all have shown to produce SeNPs of size and shape depending on time of incubation $[38,41,42]$. Further characterization of the selenium nanospheres formed by strain SeITE01 was also carried out using UV-Visible absorption spectroscopy (Figure 7). SeNPs were analyzed at three different incubation times, 6, 24 and 48 hours. All spectra presented a recurrent absorption peak at $280 \mathrm{~nm}$ probably due to the presence of aromatic amino acids, thus indicating possible adhesion of proteinaceous material on the surface of SeNPs. These data are consistent with the previously recognized occurrence of peptides and proteins associated to SeNPs of bacterial origin $[14,43,44]$. In particular, Lenz and co-workers showed that selenium nanoparticles can be coupled with a variety of high-affinity proteins. For instance, they demonstrated that a protein ( $\operatorname{Rar} A)$ next to a metalloid reductase was associated with Se-nanoparticles formed by Sulfurospirillum barnesii SES-3 [44]. The work of Debieux et al., [14] has also identified a secreted protein (SefA) from $T$. selenatis that has been demonstrated to stabilize the formation of SeNPs during selenate respiration.

\section{Mechanism of $\mathrm{SeO}_{3}{ }^{2-}$ reduction and $\mathrm{Se}^{0}$ formation in Bacillus mycoides SelTE01}

Various enzymatic systems have been proposed to explain the reduction of selenite in bacteria. In Thauera selenatis, the reaction might be catalyzed by a periplasmic dissimilatory nitrite reductase $[45,46]$ or by intracellular thiols (like 


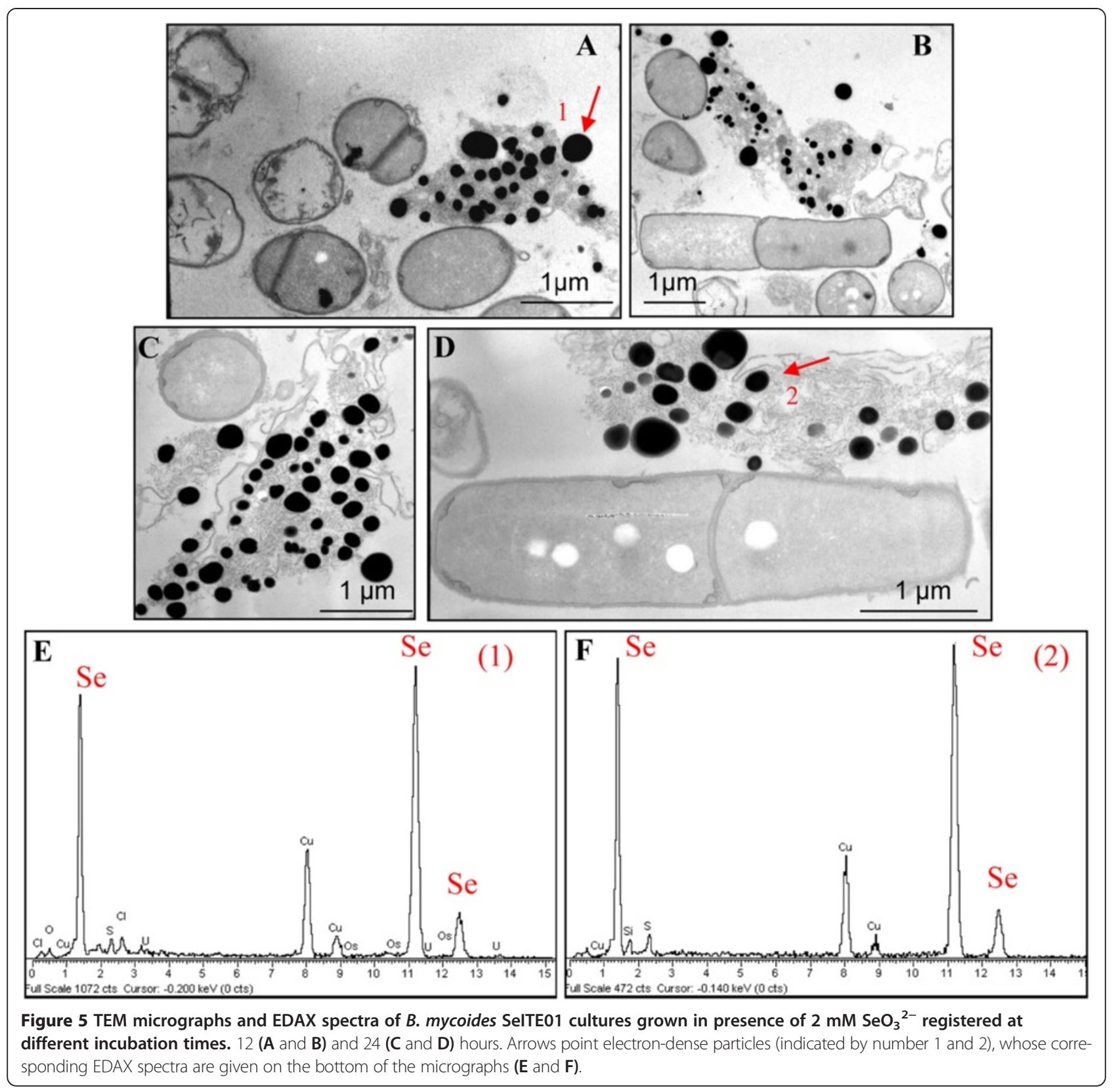

glutathione) [14]. In the case of Enterobacter cloacae reduction of $\mathrm{SeO}_{3}{ }^{2-}$ seems to rely on a nitrite reductase or may be carried out by intracellular glutathione [13,20]. A periplasmic reducing activity was proposed for the dissimilatory reduction of selenite by Bacillus selenitireducens [16]. Where enzymatic activity has been demonstrated to play a role in selenite reduction, it is mainly associated with bacterial strains capable of reducing selenium oxyanions under anaerobic conditions. In some cases, the overexpression of a single enzyme capable of reducing selenite has been ruled out. For example, in Rhodobacter sphaeroides the involvement of some chaperones, an elongation factor, and some enzymes associated with oxidative stress reactions was demonstrated [47]. Similar results were obtained by Antonioli and colleagues [48] through the proteomic analysis of soluble protein fractions in cells of Stenotrophomonas maltophilia SeITE02 grown in the presence of selenite.

Indeed, selenite can be reduced to elemental selenium by reaction with reactive thiol groups of proteins/peptides in the so called "Painter-type" reaction, which has been suggested as a general microbial detoxification reaction to oxyanions [49]. Kessi and Hanselmann [21] investigated the possible role of glutathione (GSH)/glutathione reductase (GR) system in the formation of $\mathrm{Se}^{0}$ nanoparticles from $\mathrm{SeO}_{3}{ }^{2-}$. In their experiments using the 

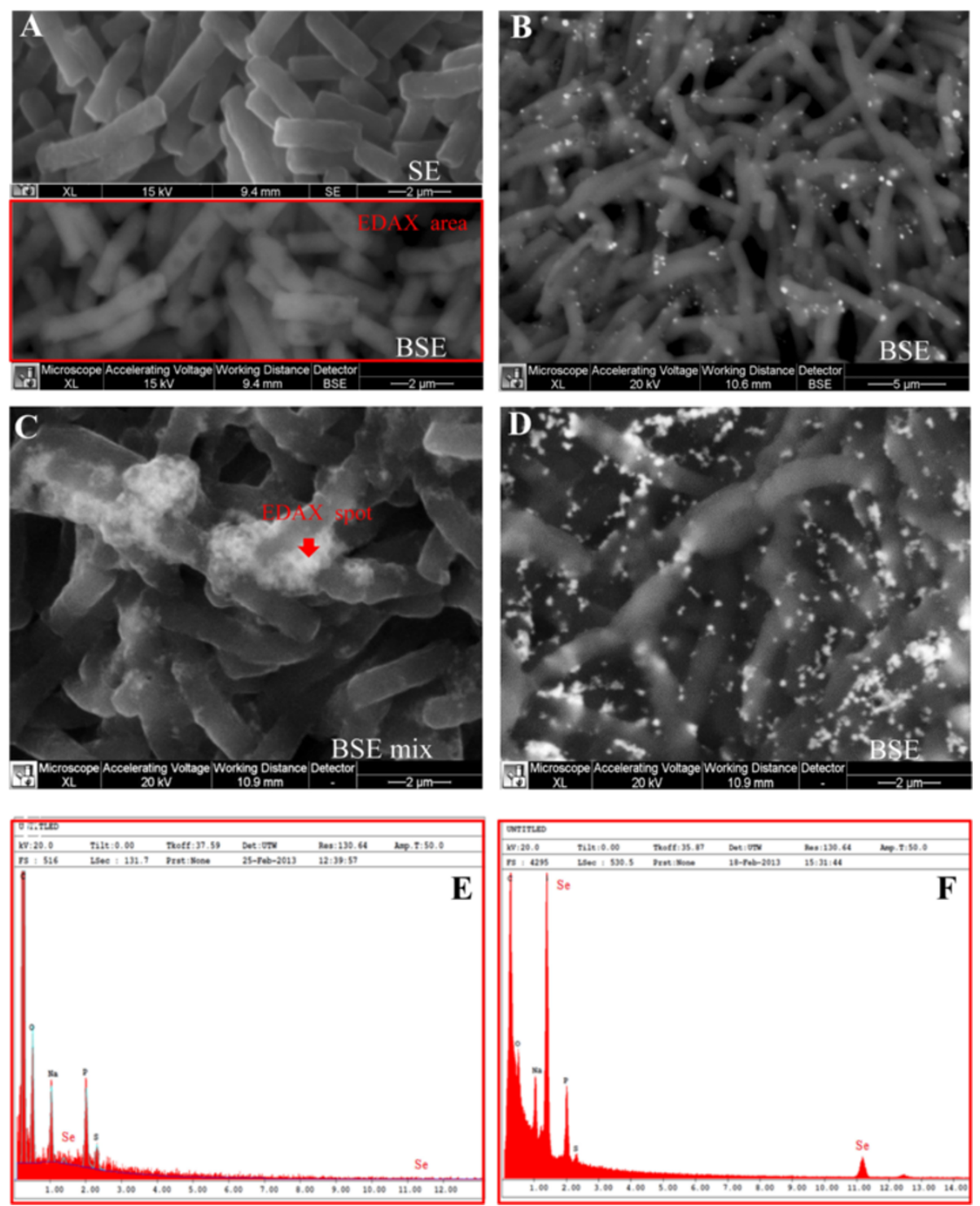

Figure 6 SEM micrographs and EDAX spectra of B. mycoides SelTE01 cultures grown in absence (A), or in presence of $2.0 \mathrm{mM} \mathrm{SeO}_{3}{ }^{2-}$, at increasing incubation times: 6 (B), 24 (C), and 48 (D) hours, in panel (E) and (F) are shown EDAX spectra corresponding to control and 24 hours SelTE01 culture, respectively. SE and BSE stand for Secondary Electrons and Back-Scattered Electrons signal, respectively.

phototrophic proteobacterium Rhodospirillum rubrum, these authors showed that the rate of selenite reduction declined when bacteria were synthesizing lower than normal levels of glutathione, while in Rhodobacter sphaeroides and Escherichia coli $\mathrm{SeO}_{3}{ }^{2-}$ reduction was reported to induce glutathione reductase activity. Garbisu and co-workers also observed a significant induction of thioredoxin and thioredoxin reductase in Bacillus subtilis exposed to millimolar concentrations of selenite [35]. This detoxification mechanism was further supported in the study by Lenz and co-workers [44], since peroxiredoxins which contain catalytic cysteine-thiols were identified in B. selenatarsenatis.
To clarify the mechanism of selenite reduction to elemental selenium in B. mycoides SeITE01, a number of $\mathrm{SeO}_{3}{ }^{2-}$-reduction assays were carried out. On the basis of electron microscopic analyses, which suggested that SeNPs formation was occurring outside the cell, cell protein fractions (i.e. cytosolic and membrane-associated) and supernatant from liquid cultures were analyzed for the presence of selenite reducing activity. Moreover, to define a possible role of exopolysaccharides (EPS) in the formation of SeNPs, a selenite reduction assay was also performed on the EPS fraction extracted from SeITE01 bacterial cultures. As shown in Figure 8, selenite reduction occurred mainly in the fraction of membrane-associated 


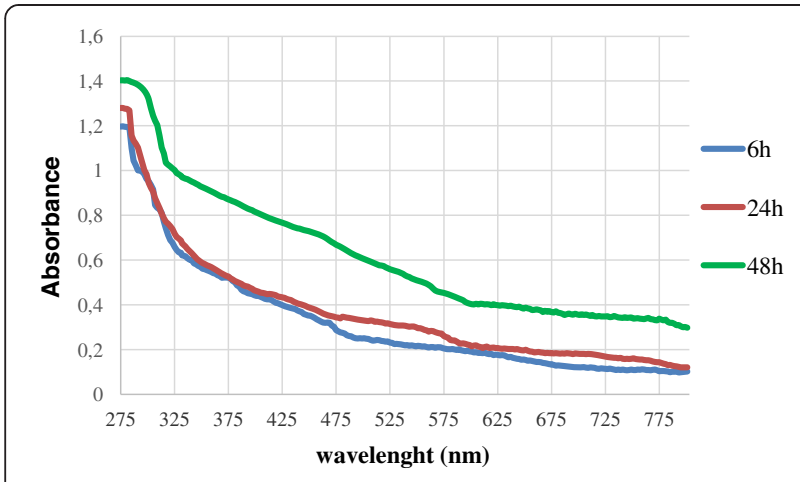

Figure 7 Time dependence of the UV-vis spectrum of SeNPs collected at different incubation times: (blue line) $6 \mathrm{~h}$, (red line) $24 \mathrm{~h}$, and (green line) $48 \mathrm{~h}$.

proteins after the addition of $\mathrm{NADH}$, with only very little activity detected in the cytosolic fraction. By contrast, no reduction activity was found in the EPS fraction (data not shown). $\mathrm{SeO}_{3}{ }^{2-}$ reduction was also observed in the supernatant of SeITE01 cultures, although again only after NADH addition. Boiling the supernatant samples resulted in a complete loss of reduction activity, inferring an enzymatic rather than chemical catalyzed reaction. Therefore, based upon the combined evidence two different mechanisms could account for the reduction of selenite into SeNPs in Bacillus mycoides SeITE01. The main mechanism is proposed to involve the action of proteins/peptides, released by bacterial cells or activated at the plasma membrane or wall surface. These proteins/ peptides may function as oxido-reductase enzymes or proton antitransporters. $\mathrm{SeO}_{3}{ }^{2-}$ would be reduced to form $\mathrm{Se}^{0}$ seeds by interacting with these proteins. Sequentially, $\mathrm{Se}^{0}$ seeds would grow into large SeNPs by further reduction of $\mathrm{SeO}_{3}{ }^{2-}$ and aggregation of Se atoms through an Ostwald ripening mechanism [24]. Meanwhile, an ancillary mechanism consisting of the intracellular reduction of selenite and involving enzymatic membrane activity may exist. In this case, SeNPs would grow inside the cell and then leak out into the extracellular space after cell lysis.

Data recorded on selenite depletion in SeITE01 cultures clearly demonstrate that the reduction of $\mathrm{SeO}_{3}{ }^{2-}$ occurs well before the appearance of $\mathrm{Se}^{0}$ nanoparticles. This might provide further support for the hypothesis that the formation mechanism of SeNPs is actually a twostep reaction. Selenite is possibly first rapidly reduced by thiol groups occurring in extracellular peptides or proteins resulting in the formation of selenides. These could then be hydrolyzed releasing nanometer-sized particles of elemental selenium which undergo extracellular precipitation.

Recently, Dwivedj and co-workers showed that Pseudomonas aeruginosa JS-11 was capable of synthesizing SeNPs trough extracellular reduction of selenite [50]. As for the strain SeITE01, a selenite reduction activity was observed in the spent medium of $P$. aeruginosa JS-11 and the involvement of NADH and NADPH dependent reductases as well as of the metabolite phenazine -1-carboxylic acid (PCA) released by strain JS-11 in the supernatant has

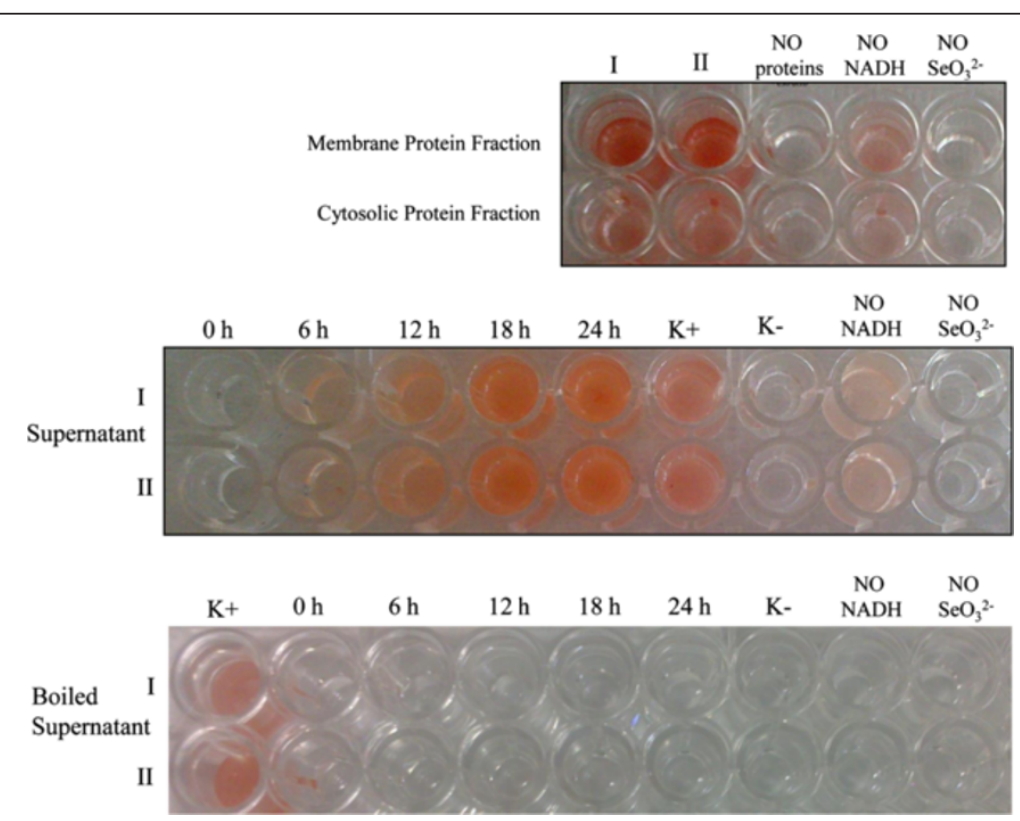

Figure 8 Selenite reduction assay carried out on protein fractions (shown at the top) and on supernatant, boiled and not boiled, (shown at the bottom) of SelTE01 liquid cultures. All tests were done in duplicate (indicated by roman numbers), with addition of $2.0 \mathrm{mM}$ $\mathrm{SeO}_{3}{ }^{2-}$ and $2.0 \mathrm{mM} \mathrm{NADH}$. Three negative controls were set up: without protein fractions or supernatant, without selenite, without NADH. 
been suggested. It is finally worth noting that a chromate reductase has been described as secreted enzymatic protein in Bacillus amyloliquefaciens [51]. In this case, the microbial cells do relay on a specific extracellular mechanism to face metal toxicity. Even more lately, a protein showing NADH-dependent reductase activity capable of converting $\mathrm{SeO}_{3}{ }^{2-}$ to $\mathrm{Se}^{0}$ has been described in cell-free extracts of Rhizobium selenitireducens [52].

However, additional experiments are needed to better understand both the nature and the release mechanism of such extracellular reductases in B. mycoides SeITE01.

\section{Conclusions}

In conclusion, the bacterial strain SeITE01 isolated from the rhizosphere of the selenium hyperaccumulator legume Astragalus bisulcatus grown in a Se contaminated soil has been taxonomically attributed to the species Bacillus mycoides on the basis of phenotypic and molecular traits. It has the ability to induce the formation of amorphous $\mathrm{Se}^{0}$ nanoparticles under aerobic conditions as a consequence of the reduction of selenite. Not only extracellular but also intracellular elemental selenium production was detected, although accumulation of SeNPs was mostly observed outside the bacterial cell. The size of SeNPs was dependent on the incubation times, showing a direct relationship between incubation time and the nanoparticle size. Increasing the incubation time increases the size of SeNPs observed. Based on the results, a tentative explanation for the process of SeNPs formation can be given (Figure 9). It is proposed that $\mathrm{SeO}_{3}{ }^{2-}$ ions are reduced into $\mathrm{Se}^{0}$ by the concourse of enzymatic proteins released by the bacterium and may also react directly with sulfhydryl groups on thiols of peptides released by Bacillus cells. Furthermore, membrane reductases may play a role in $\mathrm{SeO}_{3}{ }^{2-}$ reduction. Selenite ions once reduced form $\mathrm{Se}$ nuclei which, subsequently, grow into the large SeNPs by further reduction of $\mathrm{SeO}_{3}{ }^{2-}$ ions and an aggregation of these Se atoms, involving an Ostwald ripening mechanism [24]. Small SeNPs are then consumed for the growth of larger ones according to the Gibbs-Thomson Law [53]. As mentioned previously, SeITE01 cultures grown in the presence of selenite demonstrated the presence - although sporadic - of spherical intracellular deposits of SeNPs by TEM analysis. In this regard, bacillithiol (BSH) has been identified as a major low-molecular-weight (LMW) thiol playing a significant role in the cytosolic thiol redox chemistry of low G + C Gram-positive bacteria such Bacillus sp., concomitantly with the functions of other LMW thiols
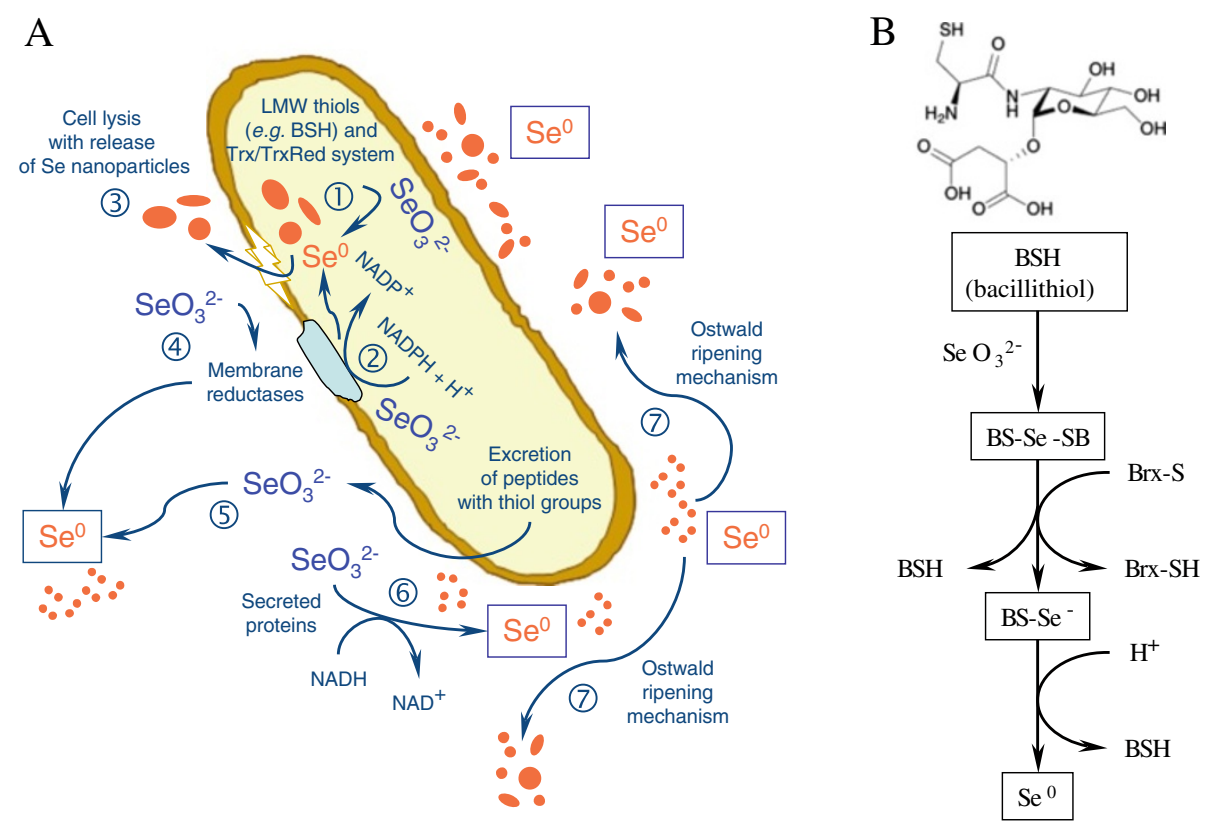

Figure 9 Hypothesis of SeNPs formation in Bacillus mycoides SelTE01. A - Synoptic schematization of proposed biogenesis mechanisms of zero-valent selenium nanoparticles in Bacillus mycoides SelTE01. (1) Cytosolic precipitation of $\mathrm{SeO}_{3}{ }^{2-}$ as $\mathrm{Se}^{0}$ nanoparticles due either to the possible activity of LMW thiols including bacillithiol (BSH) or to the Trx/TrxRed system. (2) Intracellular selenite reduction and formation of SeNPs as a consequence of presumable activity of membrane reductases. (3) Release of intracellularly generated SeNPs after cell lysis. (4) Membrane reductases may even catalyze extracellular selenite precipitation. (5) Peptides and other compounds carrying thiol groups may be released from the bacterial cell and directly react with selenite. (6) Evidence of the formation of SeNPs by Bacillus mycoides SelTE01 culture supernatant spiked with $\mathrm{SeO}_{3}{ }^{2-}$ only after $\mathrm{NADH}$ addition can be due to the presence of extracellular proteins capable of mediating selenite precipitation once provided with reducing equivalents. (7) Nascent SeNPs are inherently unstable due to their high surface area and therefore tend to grow and increase their average size to attain a lower-energy state by means of an Ostwald ripening mechanism. B - Suggested mechanism of selenite detoxification in Bacillus sp. involving Brx-like proteins, according to [55]. 
(e.g. cysteine residues) or Trx/TrxRed pathways [54]. BSHsynthesizing bacteria may contain enzymes analogous to those found in GSH-containing bacterial species, with bacilliredoxin ( $\mathrm{Brx}$ ) instead of glutaredoxin ( $\mathrm{Grx}$ ). Although the reductase system capable of maintaining $\mathrm{BSH}$ in the reduced state is not fully understood so far in Bacillus sp., the involvement of Brx-like proteins in a pathway analogous to that observed with GSH in Gramnegative bacteria may therefore be claimed in the strain SeITE01 for a complementary detoxification of selenite through reduction to $\mathrm{Se}^{0}$ with later intracellular precipitation in form of SeNPs $[55,56]$. Finally, although the formation of a selenium intermediate is only presumptive in this study, it has been previously suggested $[14,21,39,40]$ as discussed above. Therefore, additional studies have to be made to identify the possible intermediates in Bacillus mycoides SeITE01.

\section{Methods}

\section{Chemicals, culture media and solutions}

Chemicals purchased from Sigma-Aldrich (Milan, Italy) were all analytical grade. Nutrient Broth, and Bacteriological Agar were furnished by Oxoid Italia Spa (Garbagnate Milanese, Italy). $\mathrm{Na}_{2} \mathrm{SeO}_{3}$ was prepared as a $100 \mathrm{mM}$ stock solution in deionized water and sterilized by filtration.

\section{Bacterial strain SeITE01 and culture conditions}

Bacterial strain SeITE01 was obtained by means of enrichment cultures supplied with selenite $2.0 \mathrm{mM}$ from the rhizosphere of the selenium hyperaccumulator plant Astragalus bisulcatus, grown on a Se-polluted soil [26]. After isolation, the strain was maintained in Nutrient medium added with $2.0 \mathrm{mM}$ selenite. Storage was in $30 \%$ glycerol at $-80^{\circ} \mathrm{C}$.

\section{Taxonomical analyses}

Total DNA was isolated from 18-h bacterial cultures grown on Nutrient medium by using the NucleoSpin Tissue Kit (Clontech) according to manufacturer's instructions. 16S rRNA and GyrB genes were amplified through PCR using respectively F8/R11 [57] and BMSHF/BMSH-R [30] primer sets. Conditions for 16S rRNA gene amplification were as follow: $95^{\circ} \mathrm{C}$ for $5 \mathrm{~min}$, then 30 cycles of $95^{\circ} \mathrm{C}$ for $1 \mathrm{~min}, 50^{\circ} \mathrm{C}$ for $1 \mathrm{~min}, 72^{\circ} \mathrm{C}$ for $2 \mathrm{~min}$, with a final extension step at $72^{\circ} \mathrm{C}$ for $5 \mathrm{~min}$. The PCR program for GyrB gene amplification was as reported in [30].

PCR products were cloned into pGEM-T vector through the Easy T-Vector System (Promega, Italy), following the manufacturer's instructions and then sequenced on both strands (Primm, Italy). Identification of phylogenetic neighbors for $16 \mathrm{~S}$ rRNA gene sequence was initially carried out by BLAST [58] and megaBLAST [59] programs against the database of type strains with validly published prokaryotic names [28]. The fifty sequences with the highest scores were then selected for the calculation of pairwise sequence similarity using global alignment algorithm, which was implemented at the EzTaxon server (http://eztaxon-e.ezbiocloud.net/ezt_identify; [28]). GyrB sequence was searched for similarity through megaBLAST [60] relying on the NCBI database. The $16 \mathrm{~S}$ rRNA and GyrB gene sequences were registered as accession KF280239 and KF280240 in the GenBank database.

Multiple nucleotide sequences alignments were constructed using CLUSTAL_W 1.83 [60]. Phylogenetic trees were obtained using neighbor-joining algorithms within MEGA version 5.0 software package [61] with 1000 data sets examined by bootstrapping. Missing nucleotides at both the beginning and the end of the sequences were deleted before construction of the trees.

\section{Evaluation of reduction efficiency by strain SeITE01 at increasing $\mathrm{SeO}_{3}{ }^{2-}$ concentrations}

Efficiency of selenite reduction was determined for SeITE01 in rich growth medium (Nutrient Broth). All microbiological tests were carried out in 250-ml Erlenmeyer flasks containing $100 \mathrm{ml}$ of growth medium incubated at $28^{\circ} \mathrm{C}$ on an orbital shaker $(200 \mathrm{rpm})$. Each flask was inoculated with aliquots from stationary-phase cultures of the strain SeITE01 to reach a final optical density of 0.01 . Assays were performed in the presence of two different $\mathrm{Na}_{2} \mathrm{SeO}_{3}$ concentrations, namely 0.5 or $2.0 \mathrm{mM}$. Culture samples collected at different times during different tests were analyzed for bacterial growth, residual selenite in the medium, and formation of elemental Se.

\section{Microbial growth estimation}

Bacterial growth was evaluated by counting the colony forming units (CFU) on agarised Nutrient Broth plates seeded with aliquots of bacterial cultures. All analyses were performed in triplicate. Bacterial growth in presence of $\mathrm{SeO}_{3}{ }^{2-}$ was checked vs. control cultures incubated in Nutrient Broth with no $\mathrm{Na}_{2} \mathrm{SeO}_{3}$ added.

\section{$\mathrm{SeO}_{3}{ }^{2-}$ content determination}

$\mathrm{SeO}_{3}{ }^{2-}$ concentration in culture medium was measured spectrophotometrically by using the method described by [10]. This method was carried out as follow: first $10 \mathrm{ml}$ of $0.1 \mathrm{M} \mathrm{HCl}, 0.5 \mathrm{ml}$ of $0.1 \mathrm{M}$ EDTA, $0.5 \mathrm{ml}$ of $0.1 \mathrm{M} \mathrm{NaF}$, and $0.5 \mathrm{ml}$ of $0.1 \mathrm{M}$ of disodium oxalate were mixed in a $50 \mathrm{ml}$ glass bottle. A 50 - to $250-\mu \mathrm{l} \mathrm{sam}$ ple containing 100 to $200 \mathrm{nmol}$ of selenite was added, and then $2.5 \mathrm{ml}$ of $0.1 \%$ 2,3-diaminonaphthalene in $0.1 \mathrm{M} \mathrm{HCl}$ was amended. The bottles were incubated at $40^{\circ} \mathrm{C}$ for $40 \mathrm{~min}$ and then cooled to room temperature. The selenium-2,3-diaminonaphthalene complex was extracted with $6 \mathrm{ml}$ of cyclohexane by shaking the bottles vigorously for about $1 \mathrm{~min}$. The absorbance at $377 \mathrm{~nm}$ of the organic phase was determined by using 
a spectrophotometer He入ios $\beta$, Unicam. Sterile cultures were also tested for $\mathrm{SeO}_{3}{ }^{2-}$ concentration as negative controls. All manipulations were done in the dark.

Calibration curves were performed by using $0,50,100$, 150 and $200 \mathrm{nmol}$ of selenite in Nutrient broth.

\section{$\mathrm{Se}^{0}$ content determination}

$\mathrm{Se}^{0}$ concentration was measured spectrophotometrically by using the method described in [62]. A standard for elemental selenium was prepared by reducing selenite to amorphous red $\mathrm{Se}^{0}$ as follows: aliquots of a $0.1 \mathrm{M}$ sodium selenite solution were placed in test tubes to give a range of 1 to $10 \mu \mathrm{mol}$ selenite per tube. $25 \mu \mathrm{mol}$ of $\mathrm{HN}_{2} \mathrm{OH} \cdot \mathrm{HCl}$ (Sigma-Aldrich) were then added to each tube containing selenite. This concentration of hydroxylamine ensured quantitative reduction of $\mathrm{SeO}_{3}{ }^{2-}$ to $\mathrm{Se}^{0}$. The tubes were gently mixed and after 1 hour, the intensity of the red-brown selenium solution was measured at $490 \mathrm{~nm}$. To establish the $\mathrm{Se}^{0}$ standard, average values of triplicate samples were used. In order to determine the amount of selenium produced by SeITE01 strain, the bacterial culture along with the insoluble red elemental selenium was gently mixed and $10 \mathrm{ml}$ was transferred to polycarbonate centrifuge tubes. After centrifugation at $5000 \times \mathrm{g}$, bacterial cells and elemental selenium were collected as a pellet. Cells disruption was achieved by means of a sonicator equipped with a steel tip (Hielscher UP50H), by repeating 7 sonication cycles (40 seconds sonication alternated with 40 seconds of rest in ice), while keeping the samples always in ice. Once sonicated, pellets were washed twice with $10 \mathrm{ml}$ of $1 \mathrm{M} \mathrm{NaCl}$ to remove non-metabolized selenite. The red colloidal selenium in the pellet was dissolved in $10 \mathrm{ml}$ of $1 \mathrm{M} \mathrm{Na}_{2} \mathrm{~S}$ and after centrifugation to remove bacterial cells, absorption of the red-brown solution was measured at $490 \mathrm{~nm}$.

\section{Electron microscopy analysis}

Cell size and shape were identified through transmission electron microscopy (TEM) or scanning electron microscopy (SEM) starting from samples of bacterial cultures grown either in Nutrient Broth or in Nutrient Broth supplied with $2.0 \mathrm{mM} \mathrm{Na}_{2} \mathrm{SeO}_{3}$, respectively.

\section{TEM analyses}

To obtain thin sections for electron microscopy analysis, bacterial cells were embedded in Epon-araldite resin after fixation with $2.5 \%$ paraformaldehyde $+2.5 \%$ glutaraldehyde in cacodylate buffer (0.1 M cacodylate, $\mathrm{pH} 7.2)$ and post-fixation with $1 \% \mathrm{OsO}_{4}+0.15 \%$ ruthenium red in cacodylate buffer as previously reported in [63]. Sections were prepared by means of a Reichert Ultracut $\mathrm{S}$ ultramicrotome (Leica) equipped with a diamond knife. Uranyl acetate and lead citrate were used as contrast agents.

\section{SEM analyses}

Bacterial cells analyzed through scanning electron microscopy underwent the same fixation and post-fixation procedure as it has been described for TEM preparations. Once fixed, cells were dehydrated with increasing ethanol concentrations and dried through the critical point method by using liquid $\mathrm{CO}_{2}$. Cells were mounted on metallic specimens stubs and sputter-coated with carbon (MED 010 Balzers) then directly observed through the electron microscope.

TEM observations were carried out with a high resolution electron microscope Jeol JSM 5200. Whereas Energy-dispersive X-ray (EDX) analyses were performed with a high resolution electron microscope (JEOL JEM 2010) operated at high accelerating voltage (200 kV) and equipped with an Inca 100 Link analysis system. SEM observations has been done using mainly the backscattered electron (BSE) emission mode with XL30 ESEM (FEI-Philips) equipped with an EDAX micro-analytical system.

\section{Analysis of Se nanoparticles (SeNPs) \\ Recovery of selenium nanoparticles from the culturing medium}

Experiments were done using $250 \mathrm{ml}$ flasks, each containing $100 \mathrm{ml}$ of Nutrient Broth with a selenite concentration of $2 \mathrm{mM}$. After 24 and 48 hours of growth, the culture broth was centrifuged at $10020 \times g$ at $4^{\circ} \mathrm{C}$ for $10 \mathrm{~min}$. The pellet was discarded and the cell-free medium was centrifuged at $41410 \times g$ at $4^{\circ} \mathrm{C}$ for $30 \mathrm{~min}$. The supernatant was discarded and the pellet with the selenium-containing particles was re-suspended in water. The suspension was washed twice by repeating the two centrifugation steps.

\section{UV-visible spectral analysis}

Absorbance was measured using double beam UV-Vis spectrophotometer at wavelengths between 275 to $800 \mathrm{~nm}$. The SeNPs dispersed in deionised Milli- $Q$ water were stored at room temperature.

\section{Selenite reduction activity assays}

To check the selenite reduction activity by SeITE01 bacterial cultures reduction activity assays were carried out starting from different cell protein components (i.e. cytosolic and membrane-associated) as well as exopolysaccharide (EPS) fraction, and supernatant of SeITE01 liquid culture.

\section{Protein extraction}

SeITE01 cultures were grown up to log phase (18 hours of incubation) and centrifuged at $39100 \times \mathrm{g}$ (Hermle centrifuge, $\mathrm{Z} 36 \mathrm{HK})$ for $10 \mathrm{~min}$ at $4^{\circ} \mathrm{C}$ to obtain the cell pellet. Pellet was washed twice with $10 \mathrm{mM}$ Tris- $\mathrm{Cl}(\mathrm{pH}$ 7.5) and 
re-suspended in the same buffer for sonication. After sonication, the cell lysate was centrifuged at $22540 \times \mathrm{g}$ for $40 \mathrm{~min}$ to separate the soluble and membrane fractions. Total protein content was estimated by Bradford method using BSA as standard.

\section{EPS extraction}

A modification of the protocol developed by [64] was adopted. After 5 days of growth, bacterial cultures were centrifuged at $12000 \times \mathrm{g}$ for $30 \mathrm{~min}$ at $4^{\circ} \mathrm{C}$. Then, the supernatants were collected, filtered through a $0.45 \mu \mathrm{m}$ membrane and precipitated overnight with three volume of cold ethanol at $-20^{\circ} \mathrm{C}$. The precipitated polysaccharides were centrifuged at $10000 \mathrm{rpm}$ for $30 \mathrm{~min}$ at $4^{\circ} \mathrm{C}$ and resuspended in distilled water.

\section{Supernatant preparation}

Supernatant of SeITE01 cultures in Nutrient Broth medium was collected at different times during the bacterial growth curve, namely after $0,6,12,18$ and 24 hours of incubation. Samples to be analyzed were recovered by an initial centrifugation at $5000 \times \mathrm{g}$ followed by a filtration with $0.2 \mu \mathrm{m}$ disks. Heat treated samples were obtained after boiling at $121^{\circ} \mathrm{C}$ for 15 minutes.

\section{$\mathrm{SeO}_{3}{ }^{2-}$ reducing activity assay}

The activity assay to check selenite reduction was performed as follow: $100 \mu \mathrm{L}$ of proteins $\left(2 \mathrm{mg} \mathrm{mL}^{-1}\right)$ or EPS $\left(2 \mathrm{mg} \mathrm{mL}{ }^{-1}\right)$ or supernatant samples were collected in $0.2 \mathrm{~mL}$ tubes and then carefully transferred in a 96-well microtitre plate. Subsequently, $88 \mu \mathrm{L}$ of McIlvaine buffer, $10 \mu \mathrm{L}$ of $\mathrm{Na}_{2} \mathrm{SeO}_{3}{ }^{2-}$ solution (final concentration $5.0 \mathrm{mM}$ ) and $2 \mu \mathrm{L}$ of $\mathrm{NADH}$ (final concentration $2.0 \mathrm{mM}$ ) was added to each well. The mixture was then incubated at room temperature for 24 hours. Formation of red colour in the wells, indicating the production of elemental selenium, was interpreted as positive result.

\section{Competing interests}

The authors declare that they have no competing interest.

\section{Authors' contributions \\ SL carried out the whole taxonomic characterization of the strain SelTE01, performed TEM analyses, followed all selenite transformation tests, and drafted the manuscript. EZ focused on elemental selenium measurements, SeNPs UV-vis spectra, and selenite reduction assay on different protein fractions. CB participated in the revision of the manuscript. PB managed SEM-EDX analyses. CSB improved the manuscript text, also giving important suggestions for a better presentation of the results. GV, coordinator of the Research Unit of Microbial Biotechnology and Environmental Microbiology at the Department of Biotechnology - University of Verona, revised the whole manuscript and elaborated the hypothesis for selenite reduction mechanisms and elemental selenium formation in the strain SelTE01, as highlighted in Figure 9. All authors read and approved the final manuscript.}

\section{Acknowledgements}

The financial support of the Hungarian-Italian intergovernmental scientific and technological cooperation program (TET_10-1-2011-0173 and PGR_00086-2011) is gratefully acknowledged.

\section{Author details}

'Department of Biotechnology, University of Verona, Strada le Grazie 15, Verona 37134, Italy. ${ }^{2}$ Department of Neurological and Movement Sciences, Piazzale L. A. Scuro, Verona 10 - 37134, Italy. ${ }^{3}$ Biosciences, College of Life and Environmental Sciences, University of Exeter, Stocker Road, Exeter EX4 4QD, UK.

Received: 21 October 2013 Accepted: 19 February 2014 Published: 7 March 2014

\section{References}

1. Fordyce FM: Selenium deficiency and toxicity in the environment. Essent Med Geology 2013, 16:375-416.

2. Ralston NVC, Ralston CR, Blackwell JL III, Raymond LJ: Dietary and tissue selenium in relation to methylmercury toxicity. Neurotoxicology 2008, 29:802.811.

3. Keller EA: Environmental Geology. 9th edition. Upper Saddle River, NJ, USA: Prentice Hall; 2000.

4. Craig PJ, Maher W: Organoselenium compounds in the environment. In Organometallic Compounds in the Environment. 2nd edition. Edited by Craig PJ. Chichester: Wiley; 2003:391-398.

5. Barceloux DG: Selenium. J Toxicol Clin Toxicol 1999, 37(2):145-172.

6. Wu L: Review of 15 years of research on ecotoxicology and remediation of land contaminated by agricultural drainage sediment rich in selenium. Ecotoxicol Environ Saf 2004, 57(3):257-269.

7. Doran JW: Microorganisms and the biological cycling of selenium. In Advances in Microbial Ecology. Edited by Marschall KC. US: Springer; 1982:1-32.

8. Stolz JF, Basu P, Santini JM, Oremland RS: Arsenic and selenium in microbial metabolism. Annu Rev Microbiol 2006, 60:107-130.

9. Yamada A, Miyashita M, Inoue K, Matsunaga T: Extracellular reduction of selenite by a novel marine photosynthetic bacterium. Appl Microbiol Biotechnol 1997, 48(3):367-372.

10. Kessi J, Ramuz M, Wehrli E, Spycher M, Bachofen R: Reduction of selenite and detoxification of elemental selenium by the phototrophic bacterium Rhodospirillum rubrum. Appl Environ Microbiol 1999, 65(11):4734-4740.

11. Oremland RS, Herbel MJ, Blum JS, Langley S, Beveridge TJ, Ajayan PM, Sutto $T$, Ellis AV, Curran S: Structural and spectral features of selenium nanospheres produced by Se-respiring bacteria. Appl Environ Microbiol 2004, 70(1):52-60.

12. Dhanjal S, Cameotra SS: Aerobic biogenesis of selenium nanospheres by Bacillus cereus isolated from coalmine soil. Microb Cell Fact 2010, 5(9):52.

13. Ridley H, Watts CA, Richardson DJ, Butler CS: Resolution of distinct membrane-bound enzymes from Enterobacter cloacae SLD1a-1 responsible for the selective reduction of nitrate and selenate. App/ Environ Microbiol 2006, 72:5173-5180.

14. Debieux CM, Dridge EJ, Mueller CM, Splatt P, Paszkiewicz K, Knight I, Florance H, Love J, Titball RW, Lewis RJ, Richardson DJ, Butler CS: A bacterial process for selenium nanosphere assembly. Proc Natl Acad Sci USA 2011, 108 (33):13480-13485.

15. Losi ME, Frankenberger WT: Reduction of selenium oxyanions by Enterobacter cloacae SLD1a-1: isolation and growth of the bacterium and its expulsion of selenium particles. Appl Environ Microbiol 1997, 63(8):3079-3084.

16. Switzer Blum J, Burns Bindi A, Buzzelli J, Stolz JF, Oremland RS: Bacillus arsenicoselenatis, sp. nov., and Bacillus selenitireducens, sp. nov.: two haloalkaliphiles from Mono Lake, California that respire oxyanions of selenium and arsenic. Arch Microbiol 1998, 171(1):19-30.

17. Dungan RS, Yates SR, Frankenberger WT Jr: Transformations of selenate and selenite by Stenotrophomonas maltophilia isolated from a seleniferous agricultural drainage pond sediment. Environ Microbiol 2003, 5(4):287-295.

18. Kessi J: Enzymic systems proposed to be involved in the dissimilatory reduction of selenite in the purple non-sulfur bacteria Rhodospirillum rubrum and Rhodobacter capsulatus. Microbiology 2006, 152(3):731-743.

19. Schröder I, Rech S, Krafft T, Macy JM: Purification and characterization of the selenate reductase from Thauera selenatis. J Biol Chem 1997, 272(38):23765-23768.

20. Ridley H, Watts CA, Richardson DJ, Butler CS: Development of a viologenbased microtiter plate assay for the analysis of oxyanion reductase activity: application to the membrane-bound selenate reductase from Enterobacter cloacae SLD1a-1. Anal Biochem 2006, 358(2):289-294. 
21. Kessi J, Hanselmann KW: Similarities between the abiotic reduction of selenite with glutathione and the dissimilatory reaction mediated by Rhodospirillum rubrum and Escherichia coli. J Biol Chem 2004, 279:50662-50669.

22. Berger LI: Semiconductor Materials. Boca Raton, FL: CRC Press; 1997

23. Wang $H$, Zhang J, Yu H: Elemental selenium at nano size possesses lower toxicity without compromising the fundamental effect on selenoenzymes: comparison with selenomethionine in mice. Free Radic Biol Med 2007, 42:1524-1533

24. Zhang W, Chen Z, Liu H, Zhang L, Gao P, Li D: Biosynthesis and structural characteristics of selenium nanoparticles by Pseudomonas alcaliphila. Colloid Surface B 2011, 88:196-201.

25. Tran PA, Webster TJ: Selenium nanoparticles inhibit Staphylococcus aureus growth. Int J Nanomed 2011, 6:1553-1558.

26. Vallini G, Di Gregorio S, Lampis S: Rhizosphere-induced selenium precipitation for possible applications in phytoremediation of se polluted effluents. Z Naturforsch C 2005, 60(3-4):349-356.

27. Guinebretière MH, Auger S, Galleron N, Contzen M, De Sarrau B, De Buyser ML, Lamberet G, Fagerlund A, Granum PE, Lereclus D, De Vos P, Nguyen-The C, Sorokin A: Bacillus cytotoxicus sp. nov. is a novel thermotolerant species of the Bacillus cereus Group occasionally associated with food poisoning. Int $J$ Syst Evol Microbiol 2013, 63(1):31-40.

28. Chun J, Lee J-H, Jung Y, Kim M, Kim S, Kim BK, Lim Y-W: EzTaxon: a webbased tool for the identification of prokaryotes based on 16S ribosomal RNA gene sequences. Int J Syst Evol Micr 2007, 57:2259-2261.

29. Ash C, Farrow JA, Dorsch M, Stackebrandt E, Collins MD: Comparative analysis of Bacillus anthracis, Bacillus cereus, and related species on the basis of reverse transcriptase sequencing of $16 \mathrm{~S}$ rRNA. Int J Syst Bacteriol 1991, 41(3):343-346.

30. Park SH, Kim HJ, Kim JH, Kim TW, Kim HY: Simultaneous detection and identification of Bacillus cereus group bacteria using multiplex PCR. J Microbiol Biotechnol 2007, 17(7):1177-1182

31. Di Franco C, Beccari E, Santini T, Pisaneschi G, Tecce G: Colony shape as a genetic trait in the pattern-forming Bacillus mycoides. BMC Microbiol 2002, 13(2):33.

32. Lechner S, Mayr R, Francis KP, Prüss BM, Kaplan T, Wiessner-Gunkel E, Stewart GS, Scherer S: Bacillus weihenstephanensis sp. nov. is a new psychrotolerant species of the Bacillus cereus group. Int J Syst Bacteriol 1998, 48(4):1373-1382.

33. Kloepper JW, Ryu C-M, Zhang S: Induced systemic resistance and promotion of plant growth by Bacillus spp. Phytopathology 2004, 94(11):1259-1266.

34. Kumar P, Patel SK, Lee JK, Kalia VC: Extending the limits of Bacillus for novel biotechnological applications. Biotechnol Adv 2013. in press.

35. Garbisu C, Carlson D, Adamkiewicz M, Yee BC, Wong JH, Resto E, Leighton T, Buchanan BB: Morphological and biochemical responses of Bacillus subtilis to selenite stress. Biofactors 1999, 10:311-319.

36. Baesman SM, Stolz JF, Kulp TR, Oremland RS: Enrichment and isolation of Bacillus beveridgei sp. nov., a facultative anaerobic haloalkaliphile from Mono Lake, California, that respires oxyanions of tellurium, selenium, and arsenic. Extremophiles 2009, 13(4):695-705.

37. Mishra RR, Prajapati S, Das J, Dangar TK, Das N, Thatoi H: Reduction of selenite to red elemental selenium by moderately halotolerant Bacillus megaterium strains isolated from Bhitarkanika mangrove soil and characterization of reduced product. Chemosphere 2011, 84(9):1231-1237.

38. Wang T, Yang L, Zhang B, Liu J: Extracellular biosynthesis and transformation of selenium nanoparticles and application in $\mathrm{H}_{2} \mathrm{O}_{2}$ biosensor. Colloid Surface B 2010, 80(1):94-102.

39. Van Fleet-Stalder V, Chasteen TG, Pickering IJ, George GN, Prince RC: Fate of selenate and selenite metabolized by Rhodobacter sphaeroides. Appl Environ Microbiol 2000, 66:4849-4853.

40. Sarret G, Avoscan L, Carrière M, Collins R, Geoffroy N, Carrot F, Covès J, Gouget B: Chemical forms of selenium in the metal-resistant bacterium Ralstonia metallidurans $\mathrm{CH} 34$ exposed to selenite and selenate. Appl Environ Microbiol 2005, 71(5):2331-2337.

41. Torres SK, Campos VL, Leo CG, Rodriguez-Llamazares SM, Rojas SM, Gonzalez M, Smith C, Mondaca MA: Biosynthesis of selenium nanoparticles by Pantoea agglomerans and their antioxidant activity. J Nanopart Res 2012, 14:1236.

42. Tam K, Ho CT, Lee JH, Lai M, Chang CH, Rheem Y, Chen W, Hur HG, Myung NV: Growth mechanism of amorphous selenium nanoparticles synthesized by Shewanella sp. HN-41. Biosci Biotechnol Biochem 2010, 74(4):696-700
43. Dobias J, Suvorova El, Bernier-Latmani R: Role of proteins in controlling selenium nanoparticle size. Nanotechnology 2011, 22(9pp):195605.

44. Lenz M, Kolvenbach B, Gygax B, Moes S, Corvini PF: Shedding light on selenium biomineralization: proteins associated with bionanominerals. Appl Environ Microbiol 2011, 77(13):4676-4680.

45. DeMoll-Decker H, Macy JM: The periplasmic nitrite reductase of Thauera selenatis may catalyze the reduction of selenite to elemental selenium. Arch Microblol 1993, 160:241-247.

46. Butler CS, Debieux CM, Dridge EJ, Splatt P, Wright M: Biomineralization of selenium by the selenate-respiring bacterium Thauera selenatis. Biochem Soc Trans 2012, 40(6):1239-1243.

47. Bebien M, Chauvin JP, Adriano JM, Grosse S, Verméglio A: Effect of selenite on growth and protein synthesis in the phototrophic bacterium Rhodobacter sphaeroides. Appl Environ Microbiol 2001, 67(10):4440-4447.

48. Antonioli P, Lampis S, Chesini I, Vallini G, Rinalducci S, Zolla L, Righetti PG: Stenotrophomonas maltophilia SeITE02, a new bacterial strain suitable for bioremediation of selenite-contaminated environmental matrices. App/ Environ Microbiol 2007, 73(21):6854-6863.

49. Harrison JJ, Ceri H, Turner RJ: Multimetal resistance and tolerance in microbial biofilms. Nat Rev Microbiol 2007, 5:928-938.

50. Dwivedi S, AlKhedhairy AA, Ahamed M, Musarrat J: Biomimetic synthesis of selenium nanospheres by bacterial strain JS-11 and its role as a biosensor for nanotoxicity assessment: a novel Se-bioassay. PLOS One 2013, 8(3):e57404.

51. Rath BP, Das S, Mohapatra PKD, Thatoi H: Optimization of extracellular chromate reductase production by Bacillus amyloliquefaciens (CSB 9) isolated from chromite mine environment. Biocatalysis Agric Biotechnol. http://dx.doi.org/10.1016/j.bcab.2014.01.004

52. Hunter WJ: A Rhizobium selenitireducens protein showing selenite reductase activity. Curr Microbiol 2014, 68(3):311-6.

53. Elhadj S, Chernov AA, Yoreo JJD: Solvent-mediated repair and patterning of surfaces by AFM. Nanotechnology 2008, 19(10):105304-105312.

54. Gaballa A, Newton GL, Antelmann H, Parsonage D, Untone H, Rawat M, Claiborne A, Fahey RC, Helmann JD: Biosynthesis and functions of bacillithiol, a major low-molecular-weight thiol in Bacilli. Proc Natl Acad Sci USA 2010, 107(14):6482-6486.

55. Helmann JD: Bacillithiol, a new player in bacterial redox-homeostasis. Antioxid Redox Sign 2011, 15(1):123-133.

56. Sharma SV, Arbach M, Roberts AA, Macdonald CJ, Groom M, Hamilton CJ: Biophysical features of bacillithiol, the glutathione surrogate of Bacillus subtilis and other firmicutes. Chem Biochem 2013. in press.

57. Weisburg WG, Barns SM, Pelletier DA, Lane DJ: 16S ribosomal DNA amplification for phylogenetic study. J Bacteriol 1991, 173:697-703.

58. Altschul SF, Madden TL, Schäffer AA, Zhang J, Zhang Z, Miller W, Lipman DJ: Gapped BLAST and PSI-BLAST: a new generation of protein database search programs. Nucleic Acids Res 1997, 25:3389-3402

59. Zhang Z, Schwartz S, Wagner L, Miller W: A greedy algorithm for aligning DNA sequences. J Comp Biol 2000, 7:203-214.

60. Thompson JD, Gibson TJ, Plewniak F, Jeanmougin F, Higgins DG: The CLUSTAL_X windows interface: flexible strategies for multiple sequence alignment aided by quality analysis tools. Nucleic Acids Res 1997, 25:4876-4882.

61. Tamura K, Peterson D, Peterson N, Stecher G, Nei M, Kumar S: MEGA5: molecular evolutionary genetics analysis using maximum likelihood, evolutionary distance, and maximum parsimony methods. Mol Biol Evol 2011, 28:2731-2739.

62. Biswas KC, Barton LL, Tsui WL, Shuman K, Gillespie J, Eze CS: A novel method for the measurement of elemental selenium produced by bacterial reduction of selenite. J Microbiol Methods 2011, 86(2):140-144.

63. Di Gregorio S, Lampis S, Vallini G: Selenite precipitation by a rhizospheric strain of Stenotrophomonas sp. isolated from the root system of Astragalus bisulcatus: a biotechnological perspective. Environ Int 2005, 31(2):233-241.

64. Del Gallo M, Haegi A: Characterization and quantification of exocellular polysaccharides in Azospirillum brasilense and Azospirillum lipoferum. Symbiosis 1990, 9:155-161.

doi:10.1186/1475-2859-13-35

Cite this article as: Lampis et al:: Delayed formation of zero-valent selenium nanoparticles by Bacillus mycoides SelTE01 as a consequence of selenite reduction under aerobic conditions. Microbial Cell Factories 2014 13:35. 